\title{
Early Improvement of Acute Respiratory Distress Syndrome in Patients With COVID-19 in the Intensive Care Unit: Retrospective Analysis
}

Zhu Zhan ${ }^{1,2^{*}}$, PhD; Xin Yang ${ }^{3 *}$, MBBS; Hu Du ${ }^{1}$, MM; Chuanlai Zhang ${ }^{1}$, MM; Yuyan Song ${ }^{4}$, MM; Xiaoyun Ran ${ }^{1}$, MM; An Zhang ${ }^{1}$, PhD; Mei Yang ${ }^{5}$, MM

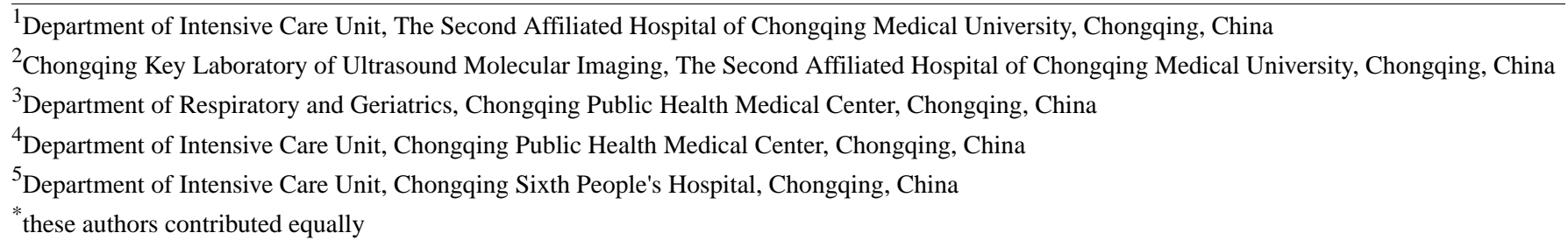

\section{Corresponding Author:}

An Zhang, PhD

Department of Intensive Care Unit

The Second Affiliated Hospital of Chongqing Medical University

76 Linjiang Rd

Yuzhong District

Chongqing, 600010

China

Phone: 8663693449

Email: zhangan@hospital.cqmu.edu.cn

\section{Abstract}

Background: Since the start of the COVID-19 pandemic, there have been over 2 million deaths globally. Acute respiratory distress syndrome (ARDS) may be the main cause of death.

Objective: This study aimed to describe the clinical features, outcomes, and ARDS characteristics of patients with COVID-19 admitted to the intensive care unit (ICU) in Chongqing, China.

Methods: The epidemiology of COVID-19 from January 21, 2020, to March 15, 2020, in Chongqing, China, was analyzed retrospectively, and 75 ICU patients from two hospitals were included in this study. On day 1, 56 patients with ARDS were selected for subgroup analysis, and a modified Poisson regression was performed to identify predictors for the early improvement of ARDS (eiARDS).

Results: Chongqing reported a 5.3\% case fatality rate for the 75 ICU patients. The median age of these patients was 57 (IQR 25-75) years, and no bias was present in the sex ratio. A total of $93 \%(n=70)$ of patients developed ARDS during ICU stay, and more than half had moderate ARDS. However, most patients $(n=41,55 \%)$ underwent high-flow nasal cannula oxygen therapy, but not mechanical ventilation. Nearly one-third of patients with ARDS improved (arterial blood oxygen partial pressure/oxygen concentration $>300 \mathrm{~mm} \mathrm{Hg}$ ) in 1 week, which was defined as eiARDS. Patients with eiARDS had a higher survival rate and a shorter length of ICU stay than those without eiARDS. Age ( $<55$ years) was the only variable independently associated with eiARDS, with a risk ratio of 2.67 (95\% CI 1.17-6.08).

Conclusions: A new subphenotype of ARDS - eiARDS - in patients with COVID-19 was identified. As clinical outcomes differ, the stratified management of patients based on eiARDS or age is highly recommended.

(JMIR Public Health Surveill 2021;7(3):e24843) doi: 10.2196/24843

\section{KEYWORDS}

acute respiratory distress syndrome; ARDS; Chongqing; COVID-19; critically ill; intensive care unit; outcome; characteristic; mortality; epidemiology; improvement 


\section{Introduction}

\section{Background}

In December 2019, Wuhan, Hubei Province, China, reported a cluster of pneumonia cases of unknown cause, later identified as COVID-19 [1]. This contagious disease is caused by SARS-CoV-2. COVID-19 was declared a pandemic by the World Health Organization (WHO) on March 11, 2020 [2]. As of January 17, 2021, 1 year has passed since the pandemic began, with more than 93 million cases and 2 million deaths reported worldwide [3].

The leading cause of COVID-19-related death may be severe respiratory failure caused by acute respiratory distress syndrome (ARDS) [4]. According to some autopsy results, the lesions primarily appear in the lungs, characterized by diffuse alveolar damage. Other organs, such as heart tissue, have no obvious histological changes [5-7]. Previous studies reported that $48.6 \%$ of patients with COVID-19 had ARDS, of whom 29\% died, and the mortality rate increased with the severity of ARDS $[8,9]$. Therefore, the characteristics of ARDS in patients with COVID-19 need to be fully understood.

This study aimed to describe the epidemiology, clinical features, laboratory findings, treatments, and outcomes of intensive care unit (ICU) patients with COVID-19 in Chongqing, China, which neighbors Hubei Province. In addition, a subphenotype of ARDS-early improvement of ARDS (eiARDS)—which occurred in about one-third of patients, was identified. eiARDS predicted a favorable clinical outcome.

\section{Methods}

\section{Study Design and Participants}

This retrospective cohort study included two cohorts of ICU patients from the Chongqing Public Health Medical Center and the Chongqing Three Gorges Central Hospital (Chongqing, China), both of which were designated hospitals for the treatment of patients with COVID-19 in Chongqing. Patients admitted to the ICU between January 21, 2020 (the date the first patient was admitted), and March 15, 2020 (the date the last patient was discharged during the first wave), were enrolled in this study.

Patients with COVID-19 were confirmed by a positive real-time reverse transcription-polymerase chain reaction (RT-PCR) assay using nasal swab specimens per WHO guidance [10]. The severity of COVID-19 was judged according to the Fifth Revised Trial Version of the Novel Coronavirus Pneumonia Diagnosis and Treatment Guidance of China [11]. Patients meeting any of the following criteria were defined as having a severe course of disease: (1) respiratory distress with a respiratory rate of more than 30 breaths per minute, (2) oxygen saturation $\leq 93 \%$ in the resting state, and (3) arterial blood oxygen partial pressure $\left(\mathrm{PaO}_{2}\right)$ /oxygen concentration $\left(\mathrm{FiO}_{2}\right) \leq 300 \mathrm{~mm} \mathrm{Hg}$. Patients meeting one of the following criteria were defined as critically ill: (1) mechanical ventilation needed as a result of respiratory failure, (2) shock, and (3) intensive care needed owing to the failure of other organs.

\section{Data Collection}

The two designated hospitals were Grade A hospitals in China, and all case data were retrieved from their electronic case system. Epidemiological and demographic data, symptoms, underlying diseases, comorbidities, treatments, clinical course, and outcome data of the patients were recorded in a spreadsheet. Vital signs, arterial blood gas analysis, laboratory data, acute physiology and chronic health evaluation II, and the sequential organ failure assessment score were recorded on specified dates (day 0: admission to hospital; day 1: admission to ICU; day 3, day 7 , and day 14) for each patient. If any question emerged regarding the case data, clarification was sought from the treating team physician. As data collection was completed, another doctor was responsible for checking and integrating the data. The proportion of pneumonia volume was calculated by the Pulmonary Infection-Assisted Diagnosis System (V1.7.1) based on computed tomography (CT) imaging.

\section{Definition}

ARDS was diagnosed according to the Berlin definition [12]. Liver injury was diagnosed according to the following criteria: alanine aminotransferase $>3$ upper limit of normal (ULN), aspartate aminotransferase $>3$ ULN, or total bilirubin $>2$ ULN, regardless of a chronic liver disease diagnosis [13]. Acute kidney injury was diagnosed on the basis of serum creatinine [14]. Cardiac injury was diagnosed if the serum concentration of hypersensitive cardiac troponin $\mathrm{T}$ was greater than the upper limit of the reference range $(>14 \mathrm{pg} / \mathrm{mL})$. Cessation of viral shedding was defined as two consecutive negative nasal swab PCR tests (with an interval of least 24 hours).

\section{Statistical Analysis}

SPSS 26.0 (IBM Corp) was used for statistical analysis. Normally distributed continuous variables were presented as mean (SD), and the independent Student $t$ test was used for comparison between two groups. The continuous variables that did not meet the criteria for normal distribution were presented as the median (IQR), and the Mann-Whitney $U$ test was used to compare differences between two groups. Categorical variables were summarized using frequencies and percentages, and the chi-square test or the Fisher exact test was used to compare two or more groups. A modified Poisson regression analysis (sandwich variance estimator) was performed to identify the predictors of eiARDS; variables with $P<.05$ in the univariate analysis were entered into the multivariate Poisson regression analysis. All tests were two sided, and $P<.05$ was considered statistically significant.

\section{Ethics Approval and Consent to Participate}

The study was approved by the Research Ethics Committee of the Second Affiliated Hospital of Chongqing Medical University, the Chongqing Public Health Medical Center, and the Chongqing Three Gorges Central Hospital. Written informed consent was waived by the ethics committees of the designated hospitals for emerging infectious diseases.

\section{Availability of Data and Materials}

Original data can be requested from the corresponding author. 


\section{Results}

\section{Clinical Characteristics of ICU Patients in Chongqing, China}

From January 21 to March 15, 2020, Chongqing reported 576 new cases of COVID-19 and 6 deaths. In this study, 75 ICU patients from two hospitals were recruited, including 48 severe patients, 27 critically ill patients, and 4 deceased patients.

A comparison of clinical characteristics between the two groups is shown in Table 1. The median age of the 75 patients was 57 years, and no bias was found in the sex ratio. Smoking was more prevalent among critically ill patients than in severe patients. The most frequent chronic medical illnesses were diabetes and hypertension. The most common symptoms were cough, fever, and dyspnea. In addition, 2 patients experienced an asymptomatic period prior to hospitalization and were dyspneic without fever during their hospital stay.

ARDS developed in most patients $(\mathrm{n}=70,93 \%)$, and more than half $(\mathrm{n}=38,51 \%)$ had moderate ARDS (Table 1). However, most patients $(n=41,55 \%)$ were supported with high-flow nasal cannula (HFNC) oxygen therapy (21 patients also received ventilation during their stay in the ICU). Only $26(35 \%)$ patients received noninvasive ventilation ( 7 patients also received invasive ventilation during their stay in the ICU), and 7 (9\%) patients received invasive ventilation. Other supportive treatments included prone-position ventilation in 7 patients, extracorporeal membrane oxygenation in 3 patients, renal replacement therapy in 3 patients, and vasoconstrictive agents in 7 patients. Although bacterial pneumonia was identified by microbiological culture of sputum or alveolar lavage fluid in only 4 patients, antibacterial agents were administered to 62 patients and antifungal agents to 12 patients. The liver was the most commonly injured extrapulmonary organ, followed by the heart and kidneys. Lymphopenia was a very noteworthy feature in these patients, with a lower incidence of leukopenia and thrombocytopenia. Antiviral agents were used in all patients; the combination of an Aluvia (lopinavir and ritonavir) tablet and interferon-alpha was the most commonly used antiviral formula $(n=69,92 \%)$, and 4 patients $(5.3 \%)$ also used ribavirin. Glucocorticoids and intravenous immunoglobulin were more commonly used in critically ill patients due to anti-inflammation properties and ability to neutralize SARS-CoV-2, respectively. Thymopeptide (thymosin alpha 1 or thymopentin) was used in most patients $(n=63,84 \%)$ to improve antiviral immunity. Traditional Chinese medicine, which is made by decoction of more than a dozen kinds of herbs, was used in $87 \%(n=65)$ of patients owing to potential antiviral and anti-inflammation properties. 
Table 1. Clinical characteristics of severe or critically ill patients with COVID-19 admitted to the intensive care unit in Chongqing, China (from January 21 to March 15, 2020).

\begin{tabular}{|c|c|c|c|c|}
\hline Characteristic & Total $(\mathrm{N}=75)$ & Severe $(n=48)$ & Critically ill $(\mathrm{n}=27)^{\mathrm{a}}$ & $P$ value \\
\hline Age (years), median (IQR) & $57(25-75)$ & $56(47-70)$ & $63(51-69)$ & .57 \\
\hline Sex & & & & .64 \\
\hline Female & $36(48)$ & $24(50)$ & $12(44)$ & \\
\hline Male & $39(52)$ & $24(50)$ & $15(56)$ & \\
\hline Smoking & $9(12)$ & $1(2)$ & $8(30)$ & .002 \\
\hline Exposure & & & & .052 \\
\hline Recent travel to Hubei Province & $16(21)$ & $13(27)$ & $3(11)$ & \\
\hline Contact with patients from Hubei Province & $24(32)$ & $18(38)$ & $6(22)$ & \\
\hline Contact with confirmed patients & $17(23)$ & $7(15)$ & $10(37)$ & \\
\hline No definite epidemiological link & $18(24)$ & $10(21)$ & $8(30)$ & \\
\hline
\end{tabular}

\section{Chronic medical illness}

Hypertension
Diabetes
Chronic cardiac disease
Chronic obstructive pulmonary disease
Malignancy

\section{Symptoms}

Fever
Cough
Expectoration
Dyspnea
Myalgia
Headache
Diarrhea

\section{Comorbidities}

Acute respiratory distress syndrome ${ }^{b}$

$$
\text { None }
$$

Mild

Moderate

Severe

Pneumothorax

Bacterial pneumonia $^{\mathrm{c}}$

Cardiac injury

Liver injury

Kidney injury

Shock

Leukopenia

Lymphopenia

Thrombocytopenia

\section{Treatment}

$\begin{array}{llll}14(19) & 8(17) & 6(22) & .55 \\ 20(27) & 12(25) & 8(30) & .66 \\ 7(9) & 6(13) & 1(4) & .40 \\ 4(5) & 4(8) & 0(0) & .31 \\ 1(1) & 1(2) & 0(0) & >.99 \\ & & & \\ 51(68) & 28(58) & 23(85) & .02 \\ 62(83) & 40(83) & 22(81) & >.99 \\ 29(39) & 21(44) & 8(30) & .23 \\ 43(57) & 23(48) & 20(74) & .03 \\ 20(27) & 12(25) & 8(30) & .66 \\ 9(12) & 7(15) & 2(7) & .58 \\ 7(9) & 4(8) & 3(11) & >.99\end{array}$

$\begin{array}{llll}70(93) & 43(90) & 27(100) & .01 \\ 5(7) & 5(10) & 0(0) & \\ 10(13) & 9(19) & 1(4) & \\ 38(51) & 25(52) & 13(48) & \\ 22(29) & 9(19) & 13(48) & .77 \\ 1(1) & 0(0) & 1(4) & >.99 \\ 4(5) & 3(6) & 1(4) & .23 \\ 14(19) & 7(15) & 7(26) & .23 \\ 19(25) & 10(21) & 9(33) & >.99 \\ 8(11) & 5(10) & 3(11) & .001 \\ 7(9) & 0(0) & 7(26) & .52 \\ 19(25) & 11(23) & 8(30) & .95 \\ 71(95) & 46(96) & 25(93) & .04 \\ 20(27) & 9(19) & 11(41) & \end{array}$

High-flow nasal cannula

$41(55)$

$20(42)$

$21(78)$ .003 


\begin{tabular}{|c|c|c|c|c|}
\hline Characteristic & Total $(\mathrm{N}=75)$ & Severe $(n=48)$ & Critically ill $(\mathrm{n}=27)^{\mathrm{a}}$ & $P$ value \\
\hline \multicolumn{5}{|l|}{ Mechanical ventilation } \\
\hline Noninvasive & $26(35)$ & $0(0)$ & $26(96)$ & $<.001$ \\
\hline Invasive & $7(9)$ & $0(0)$ & $7(26)$ & .001 \\
\hline Prone position ventilation & $7(9)$ & $0(0)$ & $7(26)$ & .001 \\
\hline Extracorporeal membrane oxygenation & $3(4)$ & $0(0)$ & $3(11)$ & .08 \\
\hline Renal replacement therapy & $3(4)$ & $0(0)$ & $3(11)$ & .08 \\
\hline Vasoconstrictive agents & $7(9)$ & $0(0)$ & $7(26)$ & .001 \\
\hline Antiviral agents & $75(100)$ & $48(100)$ & $27(100)$ & ${ }^{\mathrm{d}}$ \\
\hline Antibacterial agents & $62(83)$ & $37(77)$ & $25(93)$ & .17 \\
\hline Antifungal & $12(16)$ & $4(8)$ & $8(30)$ & .04 \\
\hline Glucocorticoids & $46(61)$ & $22(46)$ & $24(89)$ & $<.001$ \\
\hline Immunoglobulin & $30(40)$ & $13(27)$ & $17(63)$ & .002 \\
\hline Thymopeptides & $63(84)$ & $37(77)$ & $26(96)$ & .06 \\
\hline Traditional Chinese medicine & $65(87)$ & $41(85)$ & $24(89)$ & .94 \\
\hline
\end{tabular}

${ }^{\mathrm{a}}$ Four patients who died in the ICU were included.

${ }^{\mathrm{b}} \mathrm{ARDS}$ stages were defined by the worst $\mathrm{PaO}_{2} / \mathrm{FiO}_{2}$ value.

${ }^{\mathrm{c}}$ Bacterial pneumonia was confirmed by sputum or alveolar lavage fluid culture.

${ }^{\mathrm{d}}$ Not applicable.

\section{Clinical Course and Outcomes}

The clinical course and outcomes of patients with COVID-19 in Chongqing are shown in Table 2. Chongqing reported 6 deaths from COVID-19 up to March 15, 2020, with a mortality rate of $1.04 \%$ in all 576 patients. As 2 patients died in the emergency department, only 4 deceased patients with clinical data were included in this study, with a 28 -day case fatality rate of $5.3 \%$ and a 28 -day mechanical ventilation dependency of $1.3 \%$ among ICU patients. The duration from any initial symptom to diagnosis confirmed by PCR test was 5 days, to ARDS was 7 days, to ICU admission was 8 days, and to death was 16 days. The length of ICU stay was 13 days and hospital stay was 22 days. 
Table 2. Clinical course and outcomes of patients with COVID-19 admitted to the intensive care unit (ICU) in Chongqing, China (from January 21 to March 15, 2020).

\begin{tabular}{|c|c|}
\hline Clinical course and outcomes & Value \\
\hline \multicolumn{2}{|c|}{ Duration from initial symptom(s) to... ${ }^{\mathrm{a}}$ (days), median (IQR) } \\
\hline Diagnosis confirmed by $\mathrm{PCR}^{\mathrm{b}}$ test & $5(2-7)$ \\
\hline Hospital admission & $7(4-8)$ \\
\hline Acute respiratory distress syndrome & $7(6-10)$ \\
\hline ICU admission & $8(6-11)$ \\
\hline Ventilation & $10(7-14)$ \\
\hline Cessation of viral shedding ${ }^{\mathrm{c}}$ & $20(16-26)$ \\
\hline Death $^{\mathrm{d}}$ & $16(15-28)$ \\
\hline Length of ICU stay & $13(9-19)$ \\
\hline Length of hospital stay & $22(16-34)$ \\
\hline \multicolumn{2}{|l|}{ Outcomes $(\mathrm{n}=75), \mathrm{n}(\%)$} \\
\hline 28-day mortality ${ }^{\mathrm{d}}$ & $4(5.3)$ \\
\hline 28-day mechanical ventilation dependency & $1(1.3)$ \\
\hline \multicolumn{2}{|l|}{ Location of death $(n=6), n(\%)$} \\
\hline ICU & $4(66.7)$ \\
\hline Emergency department & $2(33.3)$ \\
\hline
\end{tabular}

${ }^{\mathrm{a}}$ Two patients without any symptoms until hospital admission were excluded from statistical analysis.

${ }^{\mathrm{b}} \mathrm{PCR}$ : polymerase chain reaction.

${ }^{\mathrm{c}}$ Two consecutive negative nasal swab PCR tests performed at an interval of least 24 hours).

${ }^{\mathrm{d}}$ Four patients who died in the ICU were included.

\section{Early Improvement of ARDS}

In order to clarify the characteristics of ARDS in patients with COVID-19, 56 patients with ARDS $\left(\mathrm{PaO}_{2} / \mathrm{FiO}_{2}<300 \mathrm{~mm} \mathrm{Hg}\right)$ on day 1 (first day of ICU admission) were included for a subgroup analysis. These patients were then divided into two groups based on the severity of illness on day 7: eiARDS patients with $\mathrm{PaO}_{2} / \mathrm{FiO}_{2} \geq 300 \mathrm{~mm} \mathrm{Hg}$ and non-eiARDS patients with $\mathrm{PaO}_{2} / \mathrm{FiO}_{2}<300 \mathrm{~mm} \mathrm{Hg}$ (Figure 1A).

Of the 56 patients with ARDS, a total of 18 patients had eiARDS. No significant differences were found in $\mathrm{PaO}_{2} / \mathrm{FiO}_{2}$ on day 1 (Figure 1B), the proportion of pneumonia volume on day 1 (Figure $1 \mathrm{C})$, and the rate of ventilator usage $\left(\chi^{2}=2.46\right.$,
$P=.12$ ) between the two groups. Predictably and regrettably, all the four deceased patients did not have eiARDS. Moreover, patients with eiARDS spent a shorter duration in the ICU than those without (10.5 days, IQR 8-16 vs 18 days, IQR 13-22, respectively) $(P=.001$; Figure 1D).

A Poisson regression analysis was performed to determine the factors associated with eiARDS. Table 3 shows that two variables (age and white blood cell) with $P<.05$ in the univariate analysis were chosen for multivariable analysis. Age ( $<55$ years) was the only variable independently associated with eiARDS, with a risk ratio of 2.67 (95\% CI 1.17-6.08). This finding indicated that patients younger than 55 years were 2.67 times more likely to have eiARDS than older people.

Figure 1. Comparison of patients with and without early improvement of acute respiratory distress syndrome (eiARDS). (A) All patients with ARDS on day 1, divided into two groups (eiARDS and non-eiARDS) according to $\mathrm{PaO}_{2} / \mathrm{FiO}_{2}$ on day 7. (B) No significant difference between the two groups in the $\mathrm{PaO}_{2} / \mathrm{FiO}_{2}$ on day 1. (C) No significant difference between the two groups in the proportion of pneumonia volume on day 1 . (D) The length of intensive care unit stay exhibited differences between the two groups.

A

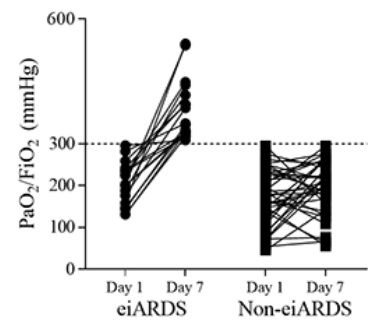

B

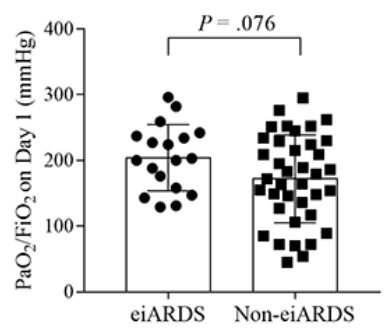

C

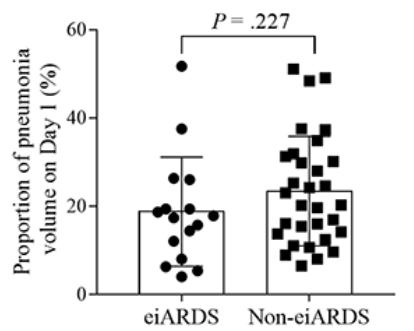

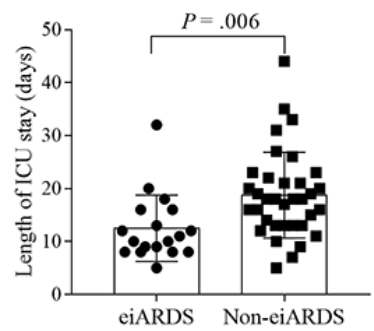


Table 3. Univariate and multivariate analysis of predictors for the early improvement of acute respiratory distress syndrome (eiARDS) in patients with COVID-19 in Chongqing, China (from January 21 to March 15, 2020).

\begin{tabular}{|c|c|c|c|c|}
\hline Characteristic & eiARDS $(n=18)$ & Non-eiARDS (n=38) & Relative risk (95\% CI) & $P$ value \\
\hline \multicolumn{5}{|l|}{ Demographic and clinical characteristics } \\
\hline \multicolumn{5}{|l|}{ Age $(\text { years })^{\mathrm{a}}, \mathbf{n}(\%)$} \\
\hline$\geq 55$ & $6(33.3)$ & $26(68.4)$ & 1 (reference) & $-{ }^{b}$ \\
\hline$<55$ (univariate) & $12(66.7)$ & $12(31.6)$ & $2.67(1.17-6.08)$ & .02 \\
\hline$<55$ (multivariate) & - & - & $2.36(1.05-5.23)$ & .04 \\
\hline Male sex (vs female), n (\%) & $12(66.7)$ & $19(50.0)$ & $1.61(0.71-3.70)$ & .26 \\
\hline $\begin{array}{l}\text { Time of symptom onset to intensive care unit admis- } \\
\text { sion, median (days) }\end{array}$ & 7.5 & 8 & $1.02(0.92-1.14)$ & .69 \\
\hline Smoking, $\mathrm{n}(\%)$ & $4(22.2)$ & $4(10.5)$ & $1.71(0.75-3.90)$ & .20 \\
\hline Hypertension, n (\%) & $2(11.2)$ & $7(18.4)$ & $0.65(0.18-2.36)$ & .52 \\
\hline Diabetes, n (\%) & $4(22.2)$ & $9(26.3)$ & $0.86(0.34-2.18)$ & .75 \\
\hline Chronic obstructive pulmonary disease, $\mathrm{n}(\%)$ & $1(5.6)$ & $3(7.9)$ & $0.77(0.13-4.36)$ & .76 \\
\hline APACHE II ${ }^{\mathrm{c}}$, median & 6.5 & 9 & $0.90(0.76-1.05)$ & .17 \\
\hline SOFA $^{\mathrm{d}}$, median & 4 & 3 & $0.97(0.67-1.42)$ & .89 \\
\hline \multicolumn{5}{|l|}{ Temperature, n (\%) } \\
\hline$<37.3{ }^{\circ} \mathrm{C}$ & $15(83.3)$ & $18(47.4)$ & 1 (reference) & - \\
\hline$\geq 37.3{ }^{\circ} \mathrm{C}$ (univariate) & $3(16.7)$ & $20(52.6)$ & $0.33(0.11-1.02)$ & .054 \\
\hline \multicolumn{5}{|l|}{ Heart rate per min, n (\%) } \\
\hline$<100$ & $13(72.2)$ & $33(86.8)$ & 1 (reference) & - \\
\hline$\geq 100$ & $5(27.8)$ & $5(13.2)$ & $1.77(0.82-3.83)$ & .15 \\
\hline \multicolumn{5}{|l|}{ Respiratory rate per min, $\mathrm{n}(\%)$} \\
\hline$<30$ & $15(83.3)$ & $37(97.4)$ & 1 (reference) & - \\
\hline$\geq 30$ & $3(16.7)$ & $1(2.6)$ & $1.17(0.48-2.86)$ & .73 \\
\hline \multicolumn{5}{|l|}{ Systolic pressure, n (\%) } \\
\hline$<140 \mathrm{~mm} \mathrm{Hg}$ & $16(88.9)$ & $35(92.1)$ & 1 (reference) & - \\
\hline$\geq 140 \mathrm{~mm} \mathrm{Hg}$ & $2(11.1)$ & $3(7.9)$ & $1.28(0.41-4.02)$ & .68 \\
\hline Ventilation (vs non) & $2(11.1)$ & $5(13.2)$ & $0.88(0.25-3.02)$ & .83 \\
\hline Proportion of pneumonia volume, median & 17.6 & 20.3 & $0.98(0.94-1.02)$ & .28 \\
\hline \multicolumn{5}{|l|}{ Laboratory findings } \\
\hline \multicolumn{5}{|l|}{ pH, n (\%) } \\
\hline $7.35-7.45$ & $4(22.2)$ & $12(31.6)$ & 1 (reference) & - \\
\hline$>7.45$ & $14(77.8)$ & $26(65.8)$ & $1.44(0.56-3.70)$ & .45 \\
\hline \multicolumn{5}{|l|}{$\mathrm{PaCO}_{2}{ }^{\mathrm{e}}, \mathbf{n}(\%)$} \\
\hline $34-45 \mathrm{~mm} \mathrm{Hg}$ & $9(50.0)$ & $21(55.3)$ & 1 (reference) & - \\
\hline$\leq 34 \mathrm{~mm} \mathrm{Hg}$ & $8(44.4)$ & $17(44.7)$ & $1.07(0.48-2.35)$ & .87 \\
\hline \multicolumn{5}{|l|}{$\mathrm{PaO}_{2} \mathbf{f}, \mathbf{n}(\%)$} \\
\hline$\geq 60 \mathrm{~mm} \mathrm{Hg}$ & $14(77.8)$ & $23(60.5)$ & 1 (reference) & - \\
\hline$<60 \mathrm{~mm} \mathrm{Hg}$ & $4(22.2)$ & $15(39.5)$ & $0.56(0.21-1.46)$ & .23 \\
\hline \multicolumn{5}{|l|}{ White blood cell count $\left(\times 10^{9} / \mathrm{L}\right)^{\mathrm{a}}, \mathrm{n}(\%)$} \\
\hline$<4$ (univariate) & 7 (38.9) & $6(16.2)$ & $2.21(1.04-4.73)$ & .04 \\
\hline
\end{tabular}




\begin{tabular}{|c|c|c|c|c|}
\hline Characteristic & eiARDS $(n=18)$ & Non-eiARDS (n=38) & Relative risk $(95 \% \mathrm{CI})$ & $P$ value \\
\hline <4 (multivariate) & - & - & $1.94(0.97-3.86)$ & .06 \\
\hline $4-10$ & $9(50.0)$ & $28(75.7)$ & 1 (reference) & - \\
\hline$>10$ (univariate) & $2(11.1)$ & $3(8.1)$ & $1.64(0.49-5.54)$ & .42 \\
\hline$>10$ (multivariate) & - & - & $1.37(0.48-3.89)$ & .55 \\
\hline Lymphocyte $\left(\times 10^{9}\right)$, median & 0.8 & 0.8 & $2.18(0.79-6.02)$ & .13 \\
\hline \multicolumn{5}{|l|}{ Platelet $\left(\times 10^{9} / \mathrm{L}\right), \mathrm{n}(\%)$} \\
\hline$\geq 100$ & $16(88.9)$ & $35(94.6)$ & 1 (reference) & - \\
\hline$<100$ & $2(11.1)$ & $2(5.4)$ & $1.59(0.55-4.60)$ & .39 \\
\hline \multicolumn{5}{|l|}{ Potassium, n (\%) } \\
\hline $3.5-4.5 \mathrm{mmol} / \mathrm{L}$ & $14(77.8)$ & $25(67.6)$ & 1 (reference) & - \\
\hline$<3.5 \mathrm{mmol} / \mathrm{L}$ & $3(16.7)$ & $11(29.7)$ & $0.61(0.21-1.82)$ & .38 \\
\hline \multicolumn{5}{|l|}{ Sodium, n (\%) } \\
\hline $135-145 \mathrm{mmol} / \mathrm{L}$ & $10(55.6)$ & $20(54.1)$ & 1 (reference) & - \\
\hline$<135 \mathrm{mmol} / \mathrm{L}$ & $8(44.4)$ & $16(43.2)$ & $1.00(0.47-2.14)$ & $>.99$ \\
\hline \multicolumn{5}{|l|}{ Albumin, n (\%) } \\
\hline$\geq 40 \mathrm{~g} / \mathrm{L}$ & $3(17.6)$ & $4(10.8)$ & 1 (reference) & - \\
\hline$<40 \mathrm{~g} / \mathrm{L}$ & $14(82.4)$ & $33(89.2)$ & $0.70(0.27-1.82)$ & .46 \\
\hline \multicolumn{5}{|l|}{ Total bilirubin, n (\%) } \\
\hline$\leq 17.1 \mu \mathrm{mol} / \mathrm{L}$ & $10(55.6)$ & $27(71.1)$ & 1 (reference) & - \\
\hline$>17.1 \mu \mathrm{mol} / \mathrm{L}$ & $8(44.4)$ & $11(28.9)$ & $1.56(0.74-3.29)$ & .25 \\
\hline \multicolumn{5}{|l|}{ Alanine aminotransferase, $\mathrm{n}(\%)$} \\
\hline$\leq 40 \mathrm{U} / \mathrm{L}$ & $13(72.2)$ & $23(60.5)$ & 1 (reference) & - \\
\hline$>40 \mathrm{U} / \mathrm{L}$ & $5(27.8)$ & $15(39.5)$ & $0.69(0.29-1.66)$ & .41 \\
\hline \multicolumn{5}{|l|}{ Creatine kinase, n (\%) } \\
\hline$\leq 200 \mathrm{U} / \mathrm{L}$ & $13(81.2)$ & $28(75.7)$ & 1 (reference) & - \\
\hline$>200 \mathrm{U} / \mathrm{L}$ & $3(18.8)$ & $9(24.3)$ & $0.67(0.27-2.32)$ & .79 \\
\hline \multicolumn{5}{|l|}{ High-sensitivity cardiac troponin T, n (\%) } \\
\hline$\leq 0.014 \mathrm{ng} / \mathrm{mL}$ & $9(90.0)$ & $19(86.4)$ & 1 (reference) & - \\
\hline$>0.014 \mathrm{ng} / \mathrm{mL}$ & $1(10.0)$ & $3(13.6)$ & $0.78(0.13-4.62)$ & .78 \\
\hline \multicolumn{5}{|l|}{ D-dimer, n (\%) } \\
\hline$\leq 0.55 \mu \mathrm{g} / \mathrm{L}$ & $9(81.8)$ & $15(39.5)$ & 1 (reference) & - \\
\hline$>0.55 \mu \mathrm{g} / \mathrm{L}$ & $2(18.2)$ & $23(60.5)$ & $0.96(0.40-2.33)$ & .93 \\
\hline \multicolumn{5}{|l|}{ Procalcitonin, n (\%) } \\
\hline$\leq 0.046 \mathrm{ng} / \mathrm{ml}$ & $8(53.3)$ & $6(16.7)$ & 1 (reference) & - \\
\hline$>0.046 \mathrm{ng} / \mathrm{ml}$ & $7(46.7)$ & $30(83.3)$ & $0.49(0.23-1.05)$ & .07 \\
\hline High-sensitivity $\mathrm{C}$ reaction protein $(\mathrm{mg} / \mathrm{L})$, median & 44.6 & 95.2 & $0.99(0.98-1.00)$ & .07 \\
\hline
\end{tabular}

${ }^{\mathrm{a}}$ Two variables (age, white blood cell count) were chosen for multivariable analysis.

${ }^{\mathrm{b}}$ Not applicable.

${ }^{\mathrm{c}}$ APACHE: acute physiology and chronic health evaluation.

${ }^{\mathrm{d}}$ SOFA: sequential organ failure assessment.

${ }^{\mathrm{e}} \mathrm{PaCO}_{2}$ : arterial partial pressure of carbon dioxide.

${ }^{\mathrm{f}} \mathrm{PaO}_{2}$ : arterial partial pressure of oxygen. 


\section{Discussion}

\section{Principal Findings}

In this study, the mortality rate associated with COVID-19 in Chongqing was $1.04 \%$, and the 28-day case fatality rate of ICU patients was $5.3 \%$. ARDS developed in $93 \%$ of ICU patients, and HFNC was the most commonly used type of oxygen therapy. About one-third of patients with ARDS improved in 1 week, which we defined as eiARDS. Patients younger than 55 years were more likely to exhibit eiARDS.

The mortality of COVID-19 varied widely across different periods and areas. In the early stage of the outbreak, Wuhan reported a mortality rate of $4.3 \%$ among hospitalized patients [15] and $61.5 \%$ among critically ill patients [16]. However, mortality in ICU patients gradually decreased to $32.5 \%-38.5 \%$ as time elapsed $[17,18]$. On the other hand, it was $26 \%$ in Lombardy, Italy [19], and 50\% in Seattle, United States [20]. In the present study, a case fatality rate of only $5.3 \%$ was reported in ICU patients in Chongqing. The large differences in mortality were probably because medical resources could not be supplied timely, including health workers and hospital beds [21]. As a matter of fact, a substantial number of health workers from other provinces provided aid to Hubei Province, alongside an increase in acute care beds [21]. Similar to the model of Hubei Province, as the first cluster cases of COVID-19 were detected in Chongqing, four designated hospitals were arranged and prepared for only patients with COVID-19, and medical experts were invited from different hospitals in Chongqing. The centralized dispatch of medical resources was key for treating COVID-19 in China.

ARDS is the primary factor that increases mortality. According to the Berlin definition, stages of mild, moderate, and severe ARDS were associated with increased mortality $(27 \%, 32 \%$, and $45 \%$, respectively) [12]. Studies showed that ARDS was one of the risk factors for death in patients with COVID-19 $[16,22]$. Much effort has been made to treat ARDS. However, only mechanical ventilation was shown to be effective [23]. Interestingly, in this study, although $93 \%$ of patients were affected by ARDS, only $35 \%$ received noninvasive ventilation and $9 \%$ received invasive ventilation. The most commonly used oxygen therapy was HFNC, which accounted for 55\% (although patients may receive both HFNC and ventilation), meaning that HFNC was effective for COVID-19-induced ARDS. Similar conclusions were observed in a previous study [4]. The authors held that HFNC was suitable for patients with COVID-19 and mild ARDS, and even safe for patients with moderate and severe outcomes, which was clearly inconsistent with the stratified treatment strategies of ARDS caused by other factors [4].

In our study, nearly one-third of patients with ARDS recovered in 1 week, which we defined as eiARDS. However, eiARDS was found in only $18 \%$ of patients with mild ARDS caused by other factors, with $36 \%$ of patients persisting and $46 \%$ worsening during the first week after ARDS onset [24]. It is worth mentioning why so many patients with COVID-19 had eiARDS and why HFNC oxygen therapy was so effective for these patients. Gattinoni et al [25] proposed two types of patients with COVID-19 pneumonia: non-ARDS type 1 and ARDS type
2. Although both types of patients met the ARDS Berlin definition, severe hypoxemia in type 1 patients was associated with nearly normal respiratory system compliance, which led to ventilation/perfusion mismatch [25]. The aforementioned problems could be explained if we assume that patients with type 1 pneumonia would improve quickly compared with those with type 2. In addition, Gattinoni et al [25] proposed that the gas volume and percentage of nonaerated tissue could be clearly distinguished via CT scan between type 1 and type 2 pneumonia. However, no differences were found in the proportion of pneumonia volume between eiARDS and non-eiARDS patients in this study.

Regardless of the reasons why the proportion of eiARDS was high, paying attention to eiARDS itself is clinically meaningful. Early or rapid improvements in ARDS has always been associated with increased survival or better outcomes [24,26]. For patients with COVID-19, early improvement in oxygenation was associated with being discharged alive from the ICU [22]. Patients with eiARDS were found to have a higher survival rate and lower length of ICU stay compared with non-eiARDS patients. Dynamic observation of ARDS in the short term was worthwhile for the prognosis of COVID-19, and patients whose ARDS did not improve in 1 week should be given more attention. If most patients had mild ARDS at baseline, that would explain the higher percentage of patients with eiARDS. However, at baseline, $38.8 \%$ of patients had moderate ARDS, and no significant differences were found between patients with and without eiARDS. In other words, the initial $\mathrm{PaO}_{2} / \mathrm{FiO}_{2}$ value was independently associated with eiARDS. Indeed, multiple studies showed that older age ( $>65$ years) was one of the risk factors for death in patients with COVID-19 [16,27-29] and establishing risk stratification through age $(>60$ years) might be helpful to clinicians [30]. Similar underlying mechanisms might be identified with regard to the effect of age on death and the development of ARDS. Nevertheless, age should be given immense attention during the management of patients with COVID-19.

\section{Limitations}

This study had several limitations. First, because of the retrospective study design, laboratory tests (except arterial blood gas analysis, which was performed daily) might not be performed for all patients at a specific time; the missing data were replaced by values obtained within the prior 2 days. Second, although the treatment strategies of the two hospitals were in accordance with the guidelines issued by the Chinese National Health Commission, some of the treatments were different, such as the composition of traditional Chinese medicine, leading to different clinical outcomes. Third, the sample size was relatively small, and some of the conclusions need to be verified using multiple care centers and larger sample sizes.

\section{Conclusions}

A new subphenotype of ARDS-eiARDS - in patients with COVID-19 was identified. As clinical outcomes differ, the stratified management of patients based on eiARDS or age is highly recommended. 


\section{Acknowledgments}

The authors thank the patients described in this study, the health care personnel who cared for them, the staff members of the Health Commission of Chongqing City, and the staff members of the Chongqing Center for Disease Control and Prevention. We thank Dr Weijun Zheng (Zhejiang Chinese Medical University, China) for his professional statistical advice.

This work was supported by Chongqing Special Research Project for Novel Coronavirus Pneumonia Prevention and Control (\#cstc2020jscx-fyzxX0012) and Emergency Research Project of COVID-19 of the Chongqing Health Commission (\#2020NCPZX04).

\section{Authors' Contributions}

$\mathrm{ZZ}$ was responsible for conceptualization, methodology, formal analysis, and writing of the original draft. XY contributed to methodology, formal analysis, and writing of the original draft. HD was involved in the investigation and project administration. $\mathrm{CZ}$ and XR contributed to the investigation. YS was responsible for the investigation and resources. AZ was responsible for conceptualization, resources, supervision, and review and editing of the manuscript. MY contributed to resources and supervision. This manuscript was approved by all authors for publication.

\section{Conflicts of Interest}

None declared.

\section{References}

1. Zhu N, Zhang D, Wang W, Li X, Yang B, Song J, et al. A Novel Coronavirus from Patients with Pneumonia in China, 2019. N Engl J Med 2020 Feb 20;382(8):727-733. [doi: 10.1056/nejmoa2001017]

2. Cucinotta D, Vanelli M. WHO Declares COVID-19 a Pandemic. Acta Biomed 2020 Mar 19;91(1):157-160 [FREE Full text] [doi: 10.23750/abm.v91i1.9397] [Medline: $\underline{\text { 32191675] }}$

3. Weekly epidemiological update - 19 January 2021. World Health Organization. 2021 Jan 19. URL: https://www.who.int/ publications/m/item/weekly-epidemiological-update---19-january-2021 [accessed 2021-03-05]

4. Li X, Ma X. Acute respiratory failure in COVID-19: is it "typical" ARDS? Crit Care 2020 May 06;24(1):198 [ㅌREE Full text] [doi: 10.1186/s13054-020-02911-9] [Medline: 32375845]

5. Xu Z, Shi L, Wang Y, Zhang J, Huang L, Zhang C, et al. Pathological findings of COVID-19 associated with acute respiratory distress syndrome. The Lancet Respiratory Medicine 2020 Apr;8(4):420-422 [FREE Full text] [doi: 10.1016/S2213-2600(20)30076-X] [Medline: 32085846]

6. Duarte-Neto AN, Monteiro RAA, da Silva LFF, Malheiros DMAC, de Oliveira EP, Theodoro-Filho J, et al. Pulmonary and systemic involvement in COVID-19 patients assessed with ultrasound-guided minimally invasive autopsy. Histopathology 2020 Aug 24;77(2):186-197 [FREE Full text] [doi: 10.1111/his.14160] [Medline: 32443177]

7. Ackermann M, Verleden SE, Kuehnel M, Haverich A, Welte T, Laenger F, et al. Pulmonary Vascular Endothelialitis, Thrombosis, and Angiogenesis in Covid-19. N Engl J Med 2020 Jul 09;383(2):120-128 [FREE Full text] [doi: 10.1056/NEJMoa2015432] [Medline: 32437596]

8. Tang X, Du R, Wang R, Cao T, Guan L, Yang C, et al. Comparison of Hospitalized Patients With ARDS Caused by COVID-19 and H1N1. Chest 2020 Jul;158(1):195-205 [FREE Full text] [doi: 10.1016/j.chest.2020.03.032] [Medline: 32224074]

9. Liu Y, Sun W, Li J, Chen L, Wang Y, Zhang L, et al. Clinical features and progression of acute respiratory distress syndrome in coronavirus disease 2019. medRxiv. Preprint posted online February 27, 2020. [doi: 10.1101/2020.02.17.20024166]

10. Clinical management of severe acute respiratory infection when novel coronavirus (nCoV) infection is suspected. World Health Organization. 2020 Jan 12. URL: https://www.who.int/publications-detail-redirect/10665-332299 [accessed 2021-03-05]

11. The Fifth Revised Trial Version of the Novel Coronavirus Pneumonia Diagnosis and Treatment Guidance. National Health Commission of the People's Republic of China. 2020 Feb 8. URL: http://www.nhc.gov.cn/yzygj/s7653p/202002/ d4b895337e19445f8d728fcaf1e3e13a.shtml [accessed 2021-03-05]

12. ARDS Definition Task Force, Ranieri VM, Rubenfeld GD, Thompson BT, Ferguson ND, Caldwell E, et al. Acute respiratory distress syndrome: the Berlin Definition. JAMA 2012 Jun 20;307(23):2526-2533. [doi: 10.1001/jama.2012.5669] [Medline: 22797452]

13. Chinese Digestion Association, Chinese Medical Doctor Association, Chinese Society of Hepatology, Chinese Medical Association. [The protocol for prevention, diagnosis and treatment of liver injury in coronavirus disease 2019]. Zhonghua Gan Zang Bing Za Zhi 2020 Mar 20;28(3):217-221. [doi: 10.3760/cma.j.cn501113-20200309-00095] [Medline: 32306655]

14. Kidney Disease: Improving Global Outcomes (KDIGO) Acute Kidney Injury Work Group. KDIGO Clinical Practice Guideline for Acute Kidney Injury. Kidney Inter Suppl 2012;2(1):1-138 [ㅍREE Full text] 
15. Wang D, Hu B, Hu C, Zhu F, Liu X, Zhang J, et al. Clinical Characteristics of 138 Hospitalized Patients With 2019 Novel Coronavirus-Infected Pneumonia in Wuhan, China. JAMA 2020 Mar 17;323(11):1061-1069 [FREE Full text] [doi: $\underline{10.1001 / j a m a .2020 .1585}$ ] [Medline: $\underline{32031570}$ ]

16. Yang X, Yu Y, Xu J, Shu H, Xia J, Liu H, et al. Clinical course and outcomes of critically ill patients with SARS-CoV-2 pneumonia in Wuhan, China: a single-centered, retrospective, observational study. Lancet Respir Med 2020 May 24;8(5):475-481 [FREE Full text] [doi: 10.1016/S2213-2600(20)30079-5] [Medline: 32105632]

17. Yu Y, Xu D, Fu S, Zhang J, Yang X, Xu L, et al. Patients with COVID-19 in 19 ICUs in Wuhan, China: a cross-sectional study. Crit Care 2020 May 14;24(1):219 [FREE Full text] [doi: 10.1186/s13054-020-02939-X] [Medline: $\underline{32410714]}$

18. Li X, Xu S, Yu M, Wang K, Tao Y, Zhou Y, et al. Risk factors for severity and mortality in adult COVID-19 inpatients in Wuhan. J Allergy Clin Immunol 2020 Jul;146(1):110-118 [FREE Full text] [doi: 10.1016/j.jaci.2020.04.006] [Medline: $\underline{32294485]}$

19. Grasselli G, Zangrillo A, Zanella A, Antonelli M, Cabrini L, Castelli A, COVID-19 Lombardy ICU Network. Baseline Characteristics and Outcomes of 1591 Patients Infected With SARS-CoV-2 Admitted to ICUs of the Lombardy Region, Italy. JAMA 2020 Apr 28;323(16):1574-1581 [FREE Full text] [doi: 10.1001/jama.2020.5394] [Medline: 32250385]

20. Bhatraju PK, Ghassemieh BJ, Nichols M, Kim R, Jerome KR, Nalla AK, et al. Covid-19 in Critically Ill Patients in the Seattle Region — Case Series. N Engl J Med 2020 May 21;382(21):2012-2022. [doi: 10.1056/nejmoa2004500]

21. Zhang Z, Yao W, Wang Y, Long C, Fu X. Wuhan and Hubei COVID-19 mortality analysis reveals the critical role of timely supply of medical resources. J Infect 2020 Jul;81(1):147-178 [FREE Full text] [doi: $\underline{10.1016 / j . j i n f .2020 .03 .018]}$ [Medline: 32209384]

22. Zangrillo A, Beretta L, Scandroglio AM, Monti G, Fominskiy E, Colombo S, COVID-BioB Study Group. Characteristics, treatment, outcomes and cause of death of invasively ventilated patients with COVID-19 ARDS in Milan, Italy. Crit Care Resusc 2020 Apr 23. [Medline: 32353223]

23. Fan E, Brodie D, Slutsky AS. Acute Respiratory Distress Syndrome: Advances in Diagnosis and Treatment. JAMA 2018 Feb 20;319(7):698-710. [doi: 10.1001/jama.2017.21907] [Medline: 29466596]

24. Pham T, Serpa Neto A, Pelosi P, Laffey JG, De Haro C, Lorente JA, LUNG SAFE Investigators*the European Society of Intensive Care Medicine Trials Group. Outcomes of Patients Presenting with Mild Acute Respiratory Distress Syndrome: Insights from the LUNG SAFE Study. Anesthesiology 2019 Feb;130(2):263-283 [FREE Full text] [doi: 10.1097/ALN.0000000000002508] [Medline: 30499850]

25. Gattinoni L, Chiumello D, Rossi S. COVID-19 pneumonia: ARDS or not? Crit Care 2020 Apr 16;24(1):154 [FREE Full text] [doi: 10.1186/s13054-020-02880-z] [Medline: $\underline{\text { 32299472] }}$

26. Schenck EJ, Oromendia C, Torres LK, Berlin DA, Choi AMK, Siempos II. Rapidly Improving ARDS in Therapeutic Randomized Controlled Trials. Chest 2019 Mar;155(3):474-482 [FREE Full text] [doi: 10.1016/j.chest.2018.09.031] [Medline: 30359616$]$

27. Du R, Liang L, Yang C, Wang W, Cao T, Li M, et al. Predictors of mortality for patients with COVID-19 pneumonia caused by SARS-CoV-2: a prospective cohort study. Eur Respir J 2020 May;55(5) [FREE Full text] [doi: 10.1183/13993003.00524-2020] [Medline: 32269088]

28. Wu C, Chen X, Cai Y, Xia J, Zhou X, Xu S, et al. Risk Factors Associated With Acute Respiratory Distress Syndrome and Death in Patients With Coronavirus Disease 2019 Pneumonia in Wuhan, China. JAMA Intern Med 2020 Jul 01;180(7):934-943 [FREE Full text] [doi: 10.1001/jamainternmed.2020.0994] [Medline: 32167524 ]

29. Zhou F, Yu T, Du R, Fan G, Liu Y, Liu Z, et al. Clinical course and risk factors for mortality of adult inpatients with COVID-19 in Wuhan, China: a retrospective cohort study. The Lancet 2020 Mar;395(10229):1054-1062. [doi: 10.1016/s0140-6736(20)30566-3]

30. Liu Y, Mao B, Liang S, Yang J, Lu H, Chai Y, Shanghai Clinical Treatment Experts Group for COVID-19. Association between age and clinical characteristics and outcomes of COVID-19. Eur Respir J 2020 May;55(5) [FREE Full text] [doi: 10.1183/13993003.01112-2020] [Medline: 32312864]

\section{Abbreviations}

ARDS: acute respiratory distress syndrome

CT: computed tomography

eiARDS: early improvement of ARDS

$\mathrm{FiO}_{2}$ : oxygen concentration

HFNC: high-flow nasal cannula

ICU: intensive care unit

$\mathbf{P a O}_{2}$ : arterial blood oxygen partial pressure

PCR: polymerase chain reaction

RT-PCR: real-time reverse transcription-polymerase chain reaction

ULN: upper limit of normal

WHO: World Health Organization 
Edited by T Sanchez; submitted 07.11.20; peer-reviewed by C Dandoy, A Hakkim; comments to author 02.02.21; revised version received 16.02.21; accepted 17.02.21; published 09.03.21

Please cite as:

Zhan Z, Yang X, Du H, Zhang C, Song Y, Ran X, Zhang A, Yang M

Early Improvement of Acute Respiratory Distress Syndrome in Patients With COVID-19 in the Intensive Care Unit: Retrospective Analysis

JMIR Public Health Surveill 2021;7(3):e24843

URL: https://publichealth.jmir.org/2021/3/e24843

doi: $10.2196 / 24843$

PMID: $\underline{3630743}$

(CZhu Zhan, Xin Yang, Hu Du, Chuanlai Zhang, Yuyan Song, Xiaoyun Ran, An Zhang, Mei Yang. Originally published in JMIR Public Health and Surveillance (http://publichealth.jmir.org), 09.03.2021. This is an open-access article distributed under the terms of the Creative Commons Attribution License (https://creativecommons.org/licenses/by/4.0/), which permits unrestricted use, distribution, and reproduction in any medium, provided the original work, first published in JMIR Public Health and Surveillance, is properly cited. The complete bibliographic information, a link to the original publication on http://publichealth.jmir.org, as well as this copyright and license information must be included. 